\title{
Peacebuilding and Mental Health: Moving beyond Individual Pathology to Community Responsibility
}

\author{
Maureen P. Flaherty ${ }^{1}$, Ellen Sikorski ${ }^{1}$, Lilya $\mathrm{Klos}^{2}$, Viktor Vus ${ }^{3}$ \\ ${ }^{1}$ Peace and Conflict Studies, University of Manitoba, Canada \\ ${ }^{2}$ Department of Sociology and Social Work, Lviv Polytechnic National University, Lviv, \\ Ukraine \\ ${ }^{3}$ Institute for Social and Political Psychology, National Academy of Educational Science, \\ Kyiv, Ukraine
}

Introduction. Strategic peacebuilding means attending to and designing systems that nest short term efforts into medium and longer-term strategies that will continue to build the whole health and strength of a community (Schirch, 2013). While this kind of attention is often not focused on a community until after it has been through war or other trauma, this paper makes a case for a focus on mental health as part of a whole-health strategy to build resilience into communities, preparing them to better cope with conflict and avert human-caused trauma, and generally providing habitus for people of all health and abilities to thrive.

Purpose. Researching "mental health and conflict" or "mental health in post-conflict societies" commonly reveals articles about post-traumatic stress disorder (PTSD) and depression (Roberts, Damundu, Lomoro, \& Sondorp, 2009), articles that focus on ex-combatants (Medeiros, 2007), with some inclusion of day-to-day stressors rather than 'not trauma' (Miller $\&$ Rasmussen, 2010). This article asserts the importance of directing the attention of the global community not only on treatment, but also on a holistic view of health and health care services that will make it impossible for any individual to believe that they are not worthy of every consideration and support to be fully functioning, empowered community members. Authors call upon psychologists, social workers and other professionals interested in peacebuilding to refocus, not away from trauma recovery, but more broadly to whole health for all communities. Design/Approach. The paper examines current barriers to mental health and wellness and provides examples of communities in Canada and Ukraine where major efforts are being made to move beyond trauma by building community resilience. Using a needs-based approach, the authors, a group of academics, citizens, mental health consumers and service providers begin with an introduction to "health" and the social determinants of health and move from a strictly medical model of health to focus on community considering what it means to be a community member, including the importance of empowerment for individuals for not only their own actualization but also the full actualization of their communities.

Results. Authors stress the clear connection between social inequities and mental health or illness and the associated stigma. The article finds that community development and peacebuilding initiatives must include strategies that address not only basic physical needs, including safety, security, and freedom from violence, but also the creation of safe places where good mental health and full social inclusion are part of the fabric of peaceful, strong communities.

Limitations and strengths. A limitation of the study is that it focuses on only two countries and does not provide empirical research. A strength is that the article deals with more than one country and combines the authors' multidisciplinary experiences to provide a new lens through which to consider mental health as part of basic community health and responsibility rather than something of individual pathology and deficit.

Summary. At the time of writing, Canada, with a population of almost 39.9 million (Worldometers, 2018), is a country without large-scale overt conflict; however, the reported incidence of domestic violence (Canadian Women's Foundation, 2016), violent crime (Statistics Canada, 2017), and homelessness (Gaetz, Dej, Richter, \& Redman, 2016) are stark 
reminders that Canadians and others living in Canada are not living in peace. The legacy of colonization of Indigenous people in the land now considered Canada has also lent to extremely high numbers of Indigenous children in government care, removed from home communities (The Guardian, 2017) with high numbers of people living with substance abuse/addictions, and/or incarcerated. Many of those in the criminal justice system, Indigenous and nonIndigenous, suffer from mental illness and addictions, with the incidence of women's mental illness being the highest (Public Services Foundation of Canada, 2015, p. 43). In addition to the mental dis-ease that accompanies trauma of all kinds, there is no internal peace for people, treated or untreated, who suffer from mental illnesses as schizophrenia (about 1 per cent of the population), bi-polar disorder, extreme depression and other mood disorders (about 12.6 per cent in their lifetime) (Pearson, Janz, \& Ali, 2015). Overall, it is estimated that in any given year 1 in 5 Canadians will experience a mental health or addictions problem or illness (Centre for Addiction and Mental Health, 2018).

Ukraine, on the other hand, is a country experiencing overt and sometimes armed conflict in the east with more than 1.6 million people registered as displaced, having migrated internally to find safety in an attempt to rebuild their lives (UNHCR, 2017). A pilot survey with university students in Lviv, more than one thousand kilometers from the armed conflict, revealed that while they seldom speak about it, youth are in mourning from having lost dear friends in the conflict and are deeply challenged to envision a future beyond the shadow of war (Flaherty \& Stavkova, 2018). In present day Ukraine, the focus on mental health has shifted from not much attention at all, to realizing the necessity to provide services for people who are directly impacted by conflict and displacement. Service provision is scant and the attention is focused largely on those dealing directly with post-traumatic stress disorder (PTSD) (Gaetz, Dej, Richter, \& Redman, 2016). The World Health Organization (WHO) estimates about 5 million people are directly affected by the conflict, including at least 1.6 million displaced. WHO also estimates that 32 per cent of those displaced suffer from post-traumatic stress disorder and 74 per cent are in need of mental health services that are not available to them (World Health Organization, 2017, p. para 1). As for the general healthcare system in Ukraine, the World Bank found that while there is a central health care system, 90 per cent of the funds allotted to mental health are contributed to psychiatric hospitals, rather than community services (World Bank, October, 2017, p. 9). This report notes that 30 per cent of Ukrainians will experience a mental disorder in their lifetime with alcohol use being more common amongst men and depression and anxiety more common amongst women. Historically, and at the time of writing, psychiatrists are seen as the authorities whose programs are funded in Ukraine, even though there are others such as psychologists and nurses who are in the community and would like to access training and provide services. As such, mental health care is expensive to maintain and brings with it a great deal of stigma to those who access it for either a common mental disorder (CMD) or an alcohol-related disorder (AUD). At present, researchers note that "poor mental health in Ukraine is tightly interconnected with poverty, unemployment and feelings of insecurity, compounded by the effects of the conflict" (ibid, p. 10).

As psychology, social work, and peace and conflict studies scholars we know that much more is needed. Rather than merely dream about it, authors share here a rallying call to approach mental health from a peacebuilding perspective and peace and conflict studies from a whole health (which includes mental health) perspective, responding rather than reacting to the needs of our shared world, creating a global "culture of peace" (Boulding, 2000).

Keywords: mental health, community building, strategic peacebuilding, whole-health strategies, Canada, Ukraine. 


\section{References.}

Canadian Women's Foundation. (2016, May). Fact Sheet: Moving women out of violence. Retrieved from https://www.canadianwomen.org/wpcontent/uploads/2017/09/FactSheet-VAWandDV_Feb_2018-Update.pdf

Centre for Addiction and Mental Health. (2018). Mental illness and addiction: Facts and statistics. Retrieved April 2018, from CAMH: https://www.camh.ca/en/drivingchange/the-crisis-is-real/mental-health-statistics

Flaherty, M. P., \& Stavkova, S. (2018). Pedagogy for social development: Building capacity through participatory action research. in progress.

Gaetz, S., Dej, E., Richter, T., \& Redman, M. (2016). The state of homelessness in Canada 2016. Toronto: Canadian Observatory on Homelessness Press. Retrieved from The state of homelessness in Canada 2016: http://homelesshub.ca/sites/default/files/SOHC16_final_20Oct2016.pdf

Medeiros, E. (2007). Integrating menatl health into post-conflict rehabilitation: The case of Sierra Leonean and Liberian 'child soldiers'. Journal of Health Psychology, 12, 498504.

Miller, K. E., \& Rasmussen, A. (2010). War exposure, daily stressors, and mental health in conflict and post-conflict settings: Bridging the divide between trauma-focused and psychosocial frameworks. Social Science and Medicine, 70(1), 7-16.

Pearson, C., Janz, T., \& Ali, J. (2015, November 27). Health at a glance: Mental and substance use disorders in Canada. Retrieved from Statistics Canada: http://www.statcan.gc.ca/pub/82-624-x/2013001/article/11855-eng.htm

Roberts, B., Damundu, E., Lomoro, O., \& Sondorp, E. (2009). Post-conflict mental health needs: A cross-section survey of trauma, depression and associataed factors in Juba, South Sudan. BMC Psychiatry, 9.

Schirch, L. (2013). Conflict assessment and peacebuilding planning: Toward a participatory approach to human security. boulder, CO: Kumarian Press.

Statistics Canada. (2017, July 24). Police-reported crime statistics in Canada, 2016. Retrieved from Statistics Canada: http://www.statcan.gc.ca/pub/85-002X/2017001/article/54842-eng.htm

UNHCR. (2017). Ukraine. Retrieved April 2018, from UNHCR: Global Focus: http://reporting.unhcr.org/Ukraine

World Bank. (October, 2017). Mental health in transition: Assessment and guidance for strengthening the integration of mental health into primary health care and community-based service platforms in Ukraine. Kyiv, Ukraine: World Bank Group.

World Health Organization. (2017, August). Health response to the humanitarian crisis in Ukraine: Facts and figures. Retrieved April 2018, from World Health Organization: http://www.euro.who.int/en/health-topics/emergencies/health-response-to-thehumanitarian-crisis-in-ukraine/facts-and-figures

World Health Organization. (n.d.). Mental health, human rights \& legislation. Retrieved February 2018, from Mental health: www.who.int/mental_health/policy/legislation/en/

Worldometers. (2018, April 23). Canadian Population. Retrieved from Worldometers: http://www.worldometers.info/world-population/canada-population/ 